\title{
Ultrastructure of Bacilli and the Bacillary Origin of the Macrophagic Inclusions in Whipple's Disease
}

\author{
By MANUEL T. SILVA, ${ }^{*}$ PAULA M. MACEDO ${ }^{1}$ \\ AND J. F. MOURA NUNES ${ }^{2}$ \\ ${ }^{1}$ Centro de Citologia Experimental da Universidade do Porto, Porto, Portugal \\ ${ }^{2}$ Laboratório de Virologia, Instituto Português de Oncologia, Lisboa, Portugal
}

(Received 15 October 1984 ; revised 10 December 1984)

\begin{abstract}
An electron microscopic and cytochemical study of the Whipple bacillus in jejunal biopsies from three untreated patients was made using fixation procedures developed for the satisfactory preservation of bacterial ultrastructure. The envelopes of the normal-looking bacilli present free in the lamina propria consisted of the following layers. (i) A cytoplasmic membrane with a triple-layered profile and a mean thickness (peak-to-peak distance) of $6.08 \mathrm{~nm}$. (ii) A thick $(20 \mathrm{~nm})$ cell wall containing peptidoglycan; the wall had a hitherto undescribed inner layer that contained polysaccharides, possibly teichoic acids. (iii) Surrounding the cell wall, a surface membrane with a symmetric profile and a mean peak-to-peak distance of $4.74 \mathrm{~nm}$. The ultrastructural pattern of the Whipple bacillus wall corresponds to that of Gram-positive bacteria, but with an additional surface membrane. This membrane is different from the outer membrane of Gram-negative bacteria because it has a symmetric profile, is thinner and has no periodic acid-Schiff (PAS)-positive components.

Normal-looking bacilli were seen very rarely inside jejunal macrophages, but degenerating bacteria were abundant in these phagocytes. Electron microscopy and ultrastructural cytochemistry of Whipple bacilli inside jejunal macrophages of the three untreated patients showed that the degenerative process is a sequence that leads to the loss of bacillary forms and to the accumulation of bacterial remnants resistant to degradation by the macrophage. These remnants correspond to the innermost, polysaccharide-containing portion of the bacillus wall. The progressive accumulation of these PAS-positive wall remnants is the origin of the intramacrophagic inclusions that are important in the histological diagnosis of Whipple's disease. The reported results indicate that in the three patients studied, the Whipple bacillus multiplies extracellularly, the bacteria that are phagocytosed by macrophages being degraded.
\end{abstract}

\section{INTRODUCTION}

Whipple's disease is a rare and peculiar disease whose pathogenic and immunological aspects are not clearly understood (Dobbins \& Kawanishi, 1981; Keren, 1981). The presence of bacillary forms in the small intestine and other affected tissues of patients with Whipple's disease, before any antibacterial treatment, has been consistently observed by several authors (Chears \& Asworth, 1961; Dobbins \& Ruffin, 1967; Dobbins \& Kawanishi, 1981; Watson \& Haubrich, 1969), and it is generally accepted that the disease results from bacterial infection (Maizel et al., 1970; Miksche et al., 1974; Watson \& Haubrich, 1969). The Whipple bacillus, the presumed causative agent of the disease, is a peculiar micro-organism: it is not cultivable in bacteriological media and its ultrastructure has been considered as not in accordance with its Gram-positive staining (Dobbins \& Kawanishi, 1981). Previous studies on the ultrastructure of the Whipple bacillus have been made in biopsy materials fixed by procedures that are adequate

Abbreviation: PAS, periodic acid-Schiff. 
for the preservation of the tissues, but do not satisfactorily preserve bacterial ultrastructure (Ryter \& Kellenberger, 1958; Silva, 1971, 1975, 1984; Silva \& Macedo, 1982, 1983a, b, $c$; Silva \& Sousa, 1973).

The macrophages in the affected tissues of Whipple's disease contain periodic acid-Schiff (PAS)-positive inclusions that are important in the histological diagnosis of the disease (Maizel et al., 1970). The PAS-positive material of these inclusions has been assumed to be polysaccharide of bacterial origin (Chears \& Asworth, 1961; Keren et al., 1976), but this has not been conclusively demonstrated. In the present paper we describe the results of an ultrastructural and cytochemical study of the degeneration of phagocytosed Whipple bacilli inside macrophages.

A better knowledge of the biology of the Whipple bacillus should aid understanding of the pathogenesis of Whipple's disease. Various reports (Fainstein et al., 1982; Roth et al., 1983; Strom \& Grunninger, 1983) have stressed the similarities between the histological characteristics of the small-bowel lesions of Whipple's disease and of cases of acquired immunodeficiency syndrome (AIDS) with massive infection with Mycobacterium avium-intracellulare, and suggestions have been made that a similar defect in cell-mediated immunity may be present in the two situations (Gillin et al., 1983; Roth et al., 1983; Strom \& Grunninger, 1983). We have now studied the Whipple bacillus lying in the jejunal lamina propria and inside jejunal macrophages by procedures that preserve bacterial ultrastructure well, and have used ultrastructural cytochemistry to permit the observation of novel details of the micromorphology of the bacillus and to demonstrate the bacillary origin of the PAS-positive inclusions of the jejunal macrophages. Some of these results have been presented in abstract form (Macedo \& Silva, 1983; Silva \& Macedo, 1983d).

\section{METHODS}

Micro-organisms. The Whipple bacillus was studied in jejunal biopsies from three untreated patients with Whipple's disease, diagnosed on the usual clinical and histological grounds. For comparative purposes, Escherichia coli (NCTC 8196) and Pseudomonas fluorescens (strain X4A) were also studied. These two Gramnegative bacteria were grown in broth containing $1.0 \%(\mathrm{w} / \mathrm{v})$ tryptone (Difco), $0.5 \%(\mathrm{w} / \mathrm{v})$ yeast extract (Difco), $0.5 \%(\mathrm{w} / \mathrm{v}) \mathrm{KCl}, \mathrm{pH} 7 \cdot 2$, at $37^{\circ} \mathrm{C}$ and $30^{\circ} \mathrm{C}$, respectively, with aeration by shaking, to the middle of the exponential phase.

Electron microscopy. The following fixation methods were used for the preparation of the biopsies: $(a) 3 \cdot 0 \%$

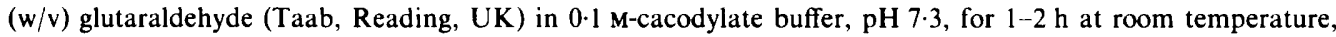
followed by $1.0 \%(\mathrm{w} / \mathrm{v}) \mathrm{OsO}_{4}$ in the same buffer, for $2 \mathrm{~h}$ at room temperature; $(b) 3.0 \%(\mathrm{w} / \mathrm{v})$ glutaraldehyde in $0.1 \mathrm{M}$-cacodylate, $\mathrm{pH} 7 \cdot 3$, supplemented with $10 \mathrm{mM}-\mathrm{Ca}^{2+}$, for $1-2 \mathrm{~h}$ at room temperature, followed by $1.0 \%(\mathrm{w} / \mathrm{v})$ $\mathrm{OsO}_{4}$ in the same buffer supplemented with $10 \mathrm{~mm}-\mathrm{Ca}^{2+}$, for $16-24 \mathrm{~h}$ at room temperature, followed by $0 \cdot 5 \%(\mathrm{w} / \mathrm{v})$ uranyl acetate in water, for $30 \mathrm{~min}$, at room temperature; $(c) 1.0 \%(\mathrm{w} / \mathrm{v}) \mathrm{OsO}_{4}$ in $\mathrm{Palade}$ 's veronal/acetate buffer (Palade, 1952), supplemented with $10 \mathrm{~mm}-\mathrm{Ca}^{2+}$, for $16 \mathrm{~h}$ at room temperature, followed by uranyl acetate as above. In all cases the biopsies were fixed immediately after collection. $E$. coli and $P$. fluorescens were pelleted from the cultures and fixed by procedure $(b)$. After ethanol dehydration, the samples were embedded in Epon (Luft, 1961) or in Epon-Araldite (Hayat, 1970). Ultrathin sections were stained with lead for $5 \mathrm{~min}$ (Venable \& Coggeshall, $1965)$, or with uranyl acetate (saturated aqueous solution of uranyl acetate and $70 \%(\mathrm{w} / \mathrm{v})$ ethanol, $2: 1$, v/v) for 1 $2 \mathrm{~min}$, followed by lead as above. Ultrathin sections mounted on gold grids were stained by the Thiéry procedure (Thiéry, 1967; Thiéry \& Rambourg, 1974) for the ultrastructural detection of polysaccharides, as described by Silva \& Macedo (1983a) and Silva et al. (1982). In some cases the sections treated by the Thiéry procedure were further stained with uranyl acetate/lead as above. Ultrathin sections mounted on gold grids were stained with phosphotungstic acid at low $\mathrm{pH}$ for the ultrastructural detection of peptidoglycan in the bacterial cell wall (Rambourg, 1971; Rosseau \& Hermier, 1975). Observations were made with Siemens Elmiskops IA and 102.

Microdensitometry. Photographic negatives were examined with a Joyce-Loebl microdensitometer MK III CS, set to an arm ratio of $20 \times$ and a slit width of $0.5 \mathrm{~nm}$. The microscopes were calibrated with a grating grid.

\section{RESULTS}

The microbial flora found in the jejunal biopsies from the three patients consisted of bacteria with identical micromorphological characteristics. Normal-looking bacilli, including some undergoing division, were almost exclusively found in the lamina propria (Fig. 1). Macrophageingested bacilli were in different stages of degradation as described below. 


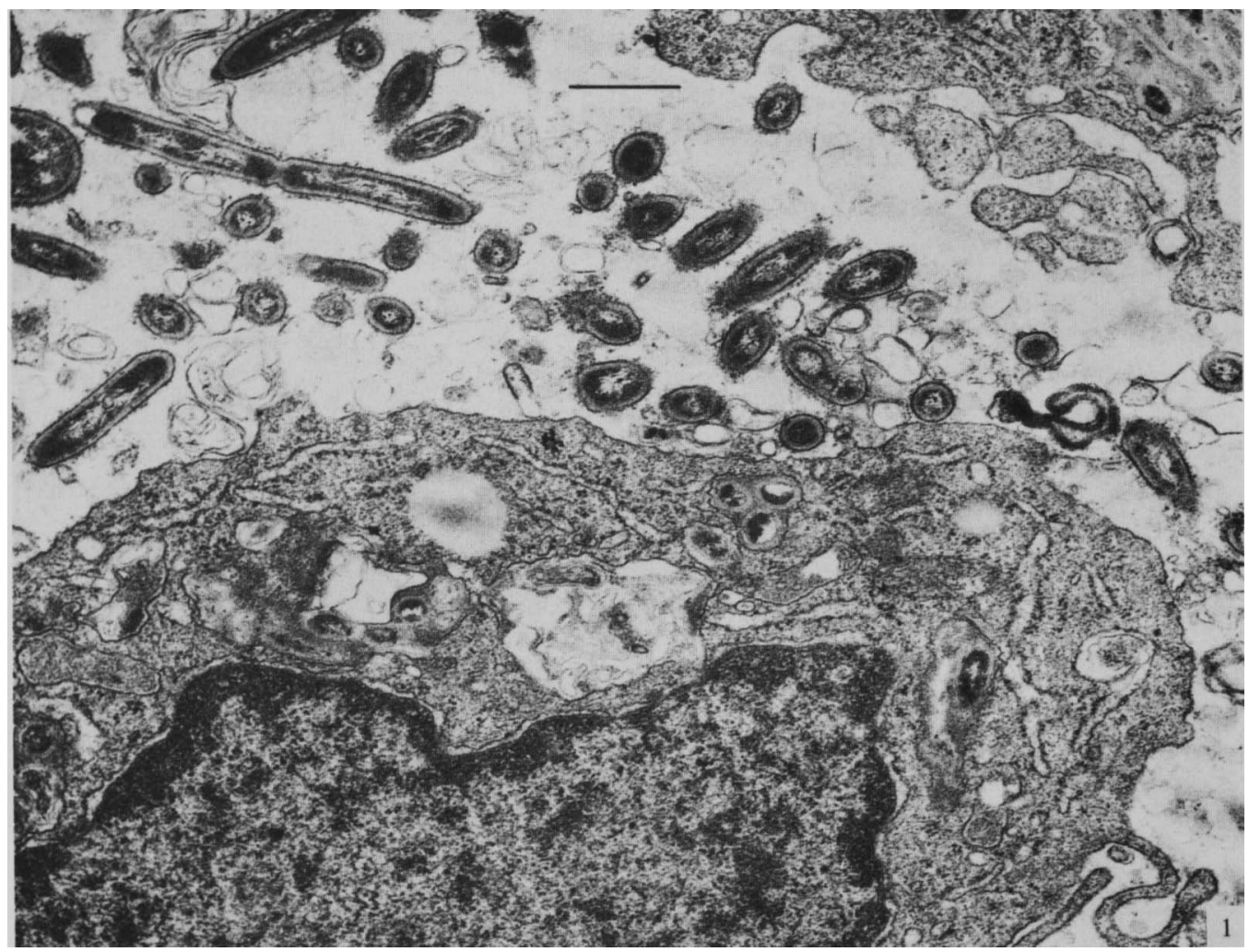

Fig. 1. Low-power view of the jejunal lamina propria from an untreated patient with Whipple's disease. Fixation with glutaraldehyde $+\mathrm{Ca}^{2+} / \mathrm{OsO}_{4}+\mathrm{Ca}^{2+} /$ uranyl acetate (method $b$ ). Notice the presence of several bacilli free in the intercellular space; they have a normal-looking ultrastructure and one of them is dividing. Inside the two macrophages several bacilli undergoing degradation are present. Section stained with uranyl acetate/lead. Bar, $1 \mu \mathrm{m}$.

Ultrastructure of normal-looking bacilli. Normal-looking bacilli were present free in the lamina propria. After fixation by procedure $(c)$ the following features were visible in representative samples (Figs 2-5).

Cell envelopes. Several layers were seen in lead- or uranyl acetate/lead-stained sections. Very conspicuous was a surface membrane (Fig. 2, SM) with a symmetric profile, as shown by microdensitometry (Fig. 6, SM) and a mean peak-to-peak distance of $4.75 \mathrm{~nm}$. This membrane surrounded a granular, low density layer (Fig. 2, W) with a mean thickness of $20 \mathrm{~nm}$ (Fig. 6, W). The inner portion of the envelope exhibited three electron-dense layers (Fig. 2, L1, L2, L3; Fig. 6 - microdensitometric tracing). In some sections only two layers were visible; they corresponded to L1 and L2, L3 being masked by the cytoplasmic surface. This explains the fact that L3 was most clearly visible in some partially lysed cells (see below).

In sections stained for polysaccharides by the Thiéry procedure, a layer of PAS-positive material was revealed (Fig. 3). To assess the topology of that layer better we used uranyl acetate/lead staining after the staining by the Thiéry technique (Fig. 4), which allowed us to identify the PAS-positive layer as L1. Staining with phosphotungstic acid at low $\mathrm{pH}$ contrasted $\mathrm{Ll}$ and the thick layer between $\mathrm{Ll}$ and the surface membrane (Fig. 5). The surface membrane was Thiéry-negative and did not stain with phosphotungstic acid at low $\mathrm{pH}$.

Intracellular compartment. In this compartment, granules with the characteristics of ribosomes, and DNA fibrils, were present (Fig. 2). No other components were seen. 


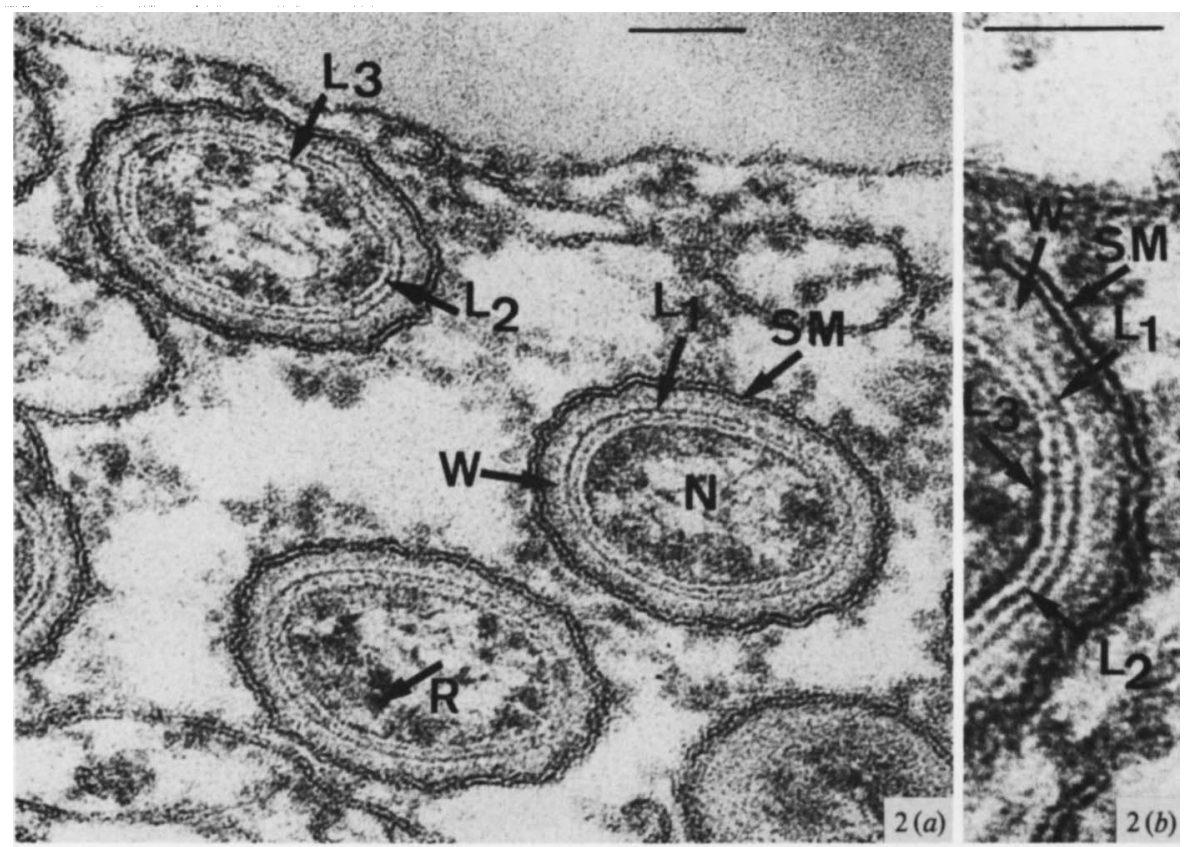

Fig. 2. Cross section of Whipple bacilli free in the lamina propria in a jejunal biopsy fixed with $\mathrm{OsO}_{4}+\mathrm{Ca}^{2+} /$ uranyl acetate (method $c$ ). SM, surface membrane with a symmetric profile; W, cell wall with an inner electron-dense layer (L1); L2 and L3, the two electron-dense layers of the cytoplasmic membrane; R, ribosomes; N, DNA fibrils. Section stained with uranyl acetate/lead. Bars, $100 \mathrm{~nm}$.
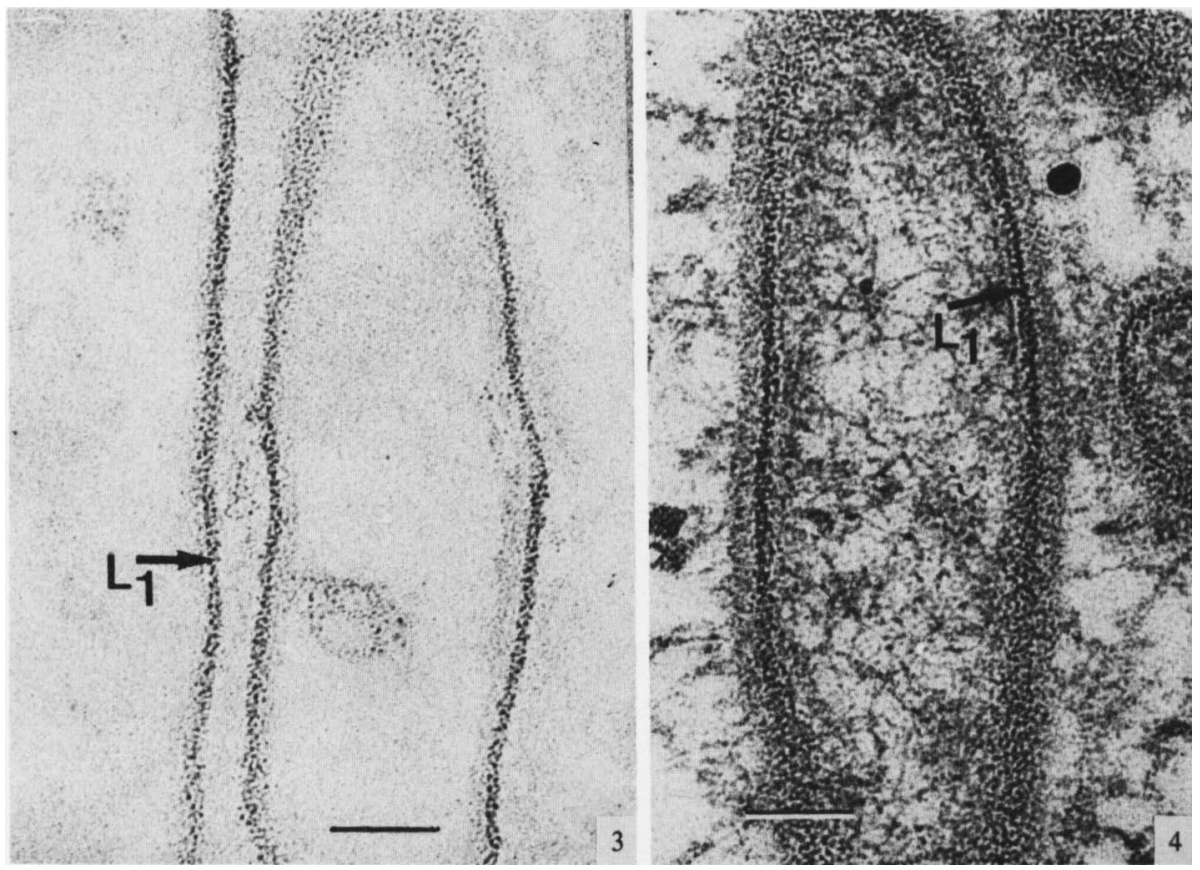

Fig. 3. Same sample as in Fig. 2 but section stained by the Thiéry method. Notice the strong silver staining (PAS-positive) of layer L1. Bar, $100 \mathrm{~nm}$.

Fig. 4. As in Fig. 3 but Thiéry method followed by uranyl acetate/lead staining. Although the surface and cytoplasmic membranes are not well visualized (because the periodic acid treatment used in the Thiéry procedure removes bound osmium and therefore interferes with uranyl and lead staining of membranes), the contrast imparted to the envelope structure makes it clear that the Thiéry-positive layer is L1. Bar $100 \mathrm{~nm}$. 

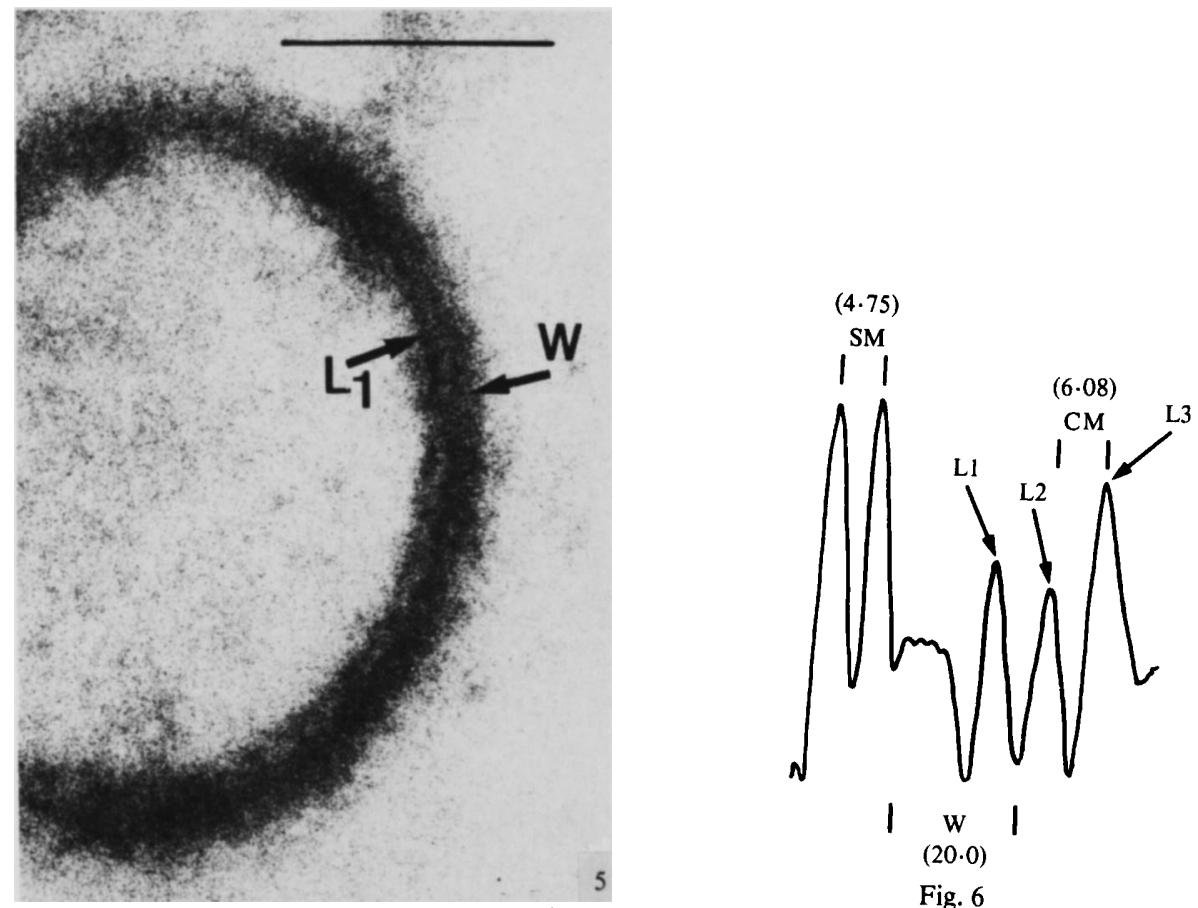

Fig. 6

Fig. 5. Staining with phosphotungstic acid at low $\mathrm{pH}$ of a sample identical to that in Fig. 2. Both L1 and the thick layer around it are stained. Bar, $100 \mathrm{~nm}$.

Fig. 6 Microdensitometric tracing of the envelope of the bacillus shown in Fig. 2(b). Notice the symmetric profile of the surface membrane (SM) and the three peaks corresponding to layers L1, L2 and L3. W, zone corresponding to the cell wall; CM, cytoplasmic membrane. The mean values (in $\mathrm{nm}$ ) for the peak-to-peak distances to the envelope layers are indicated in parentheses.

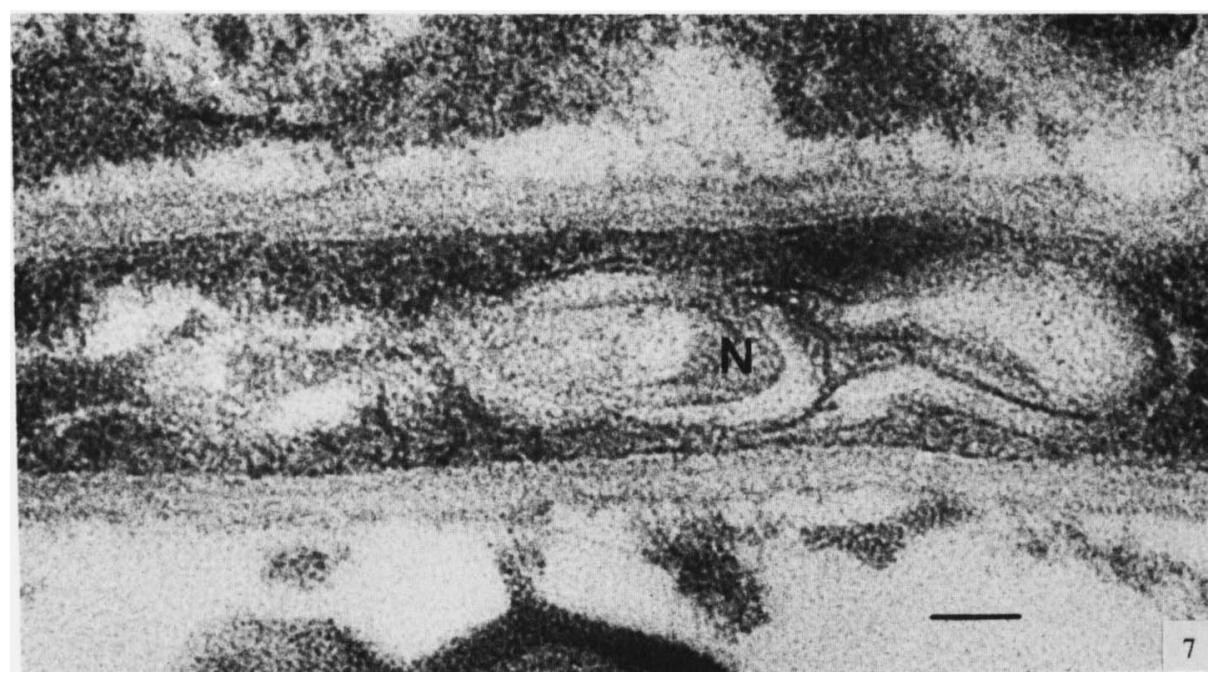

Fig. 7. A Whipple bacillus free in the lamina propria in a jejunal biopsy fixed with glutaraldehyde $/ \mathrm{OsO}_{4}$ without $\mathrm{Ca}^{2+}$ and $\mathrm{UO}_{2}^{2+}(\operatorname{method} a)$. Notice the poor preservation of most of the bacillary components. The envelope layers are not clear, the cytoplasm has no ribosomes and the DNA fibrils are aggregated $(\mathrm{N})$. Section stained with uranyl acetate/lead. Bar, $100 \mathrm{~nm}$. 

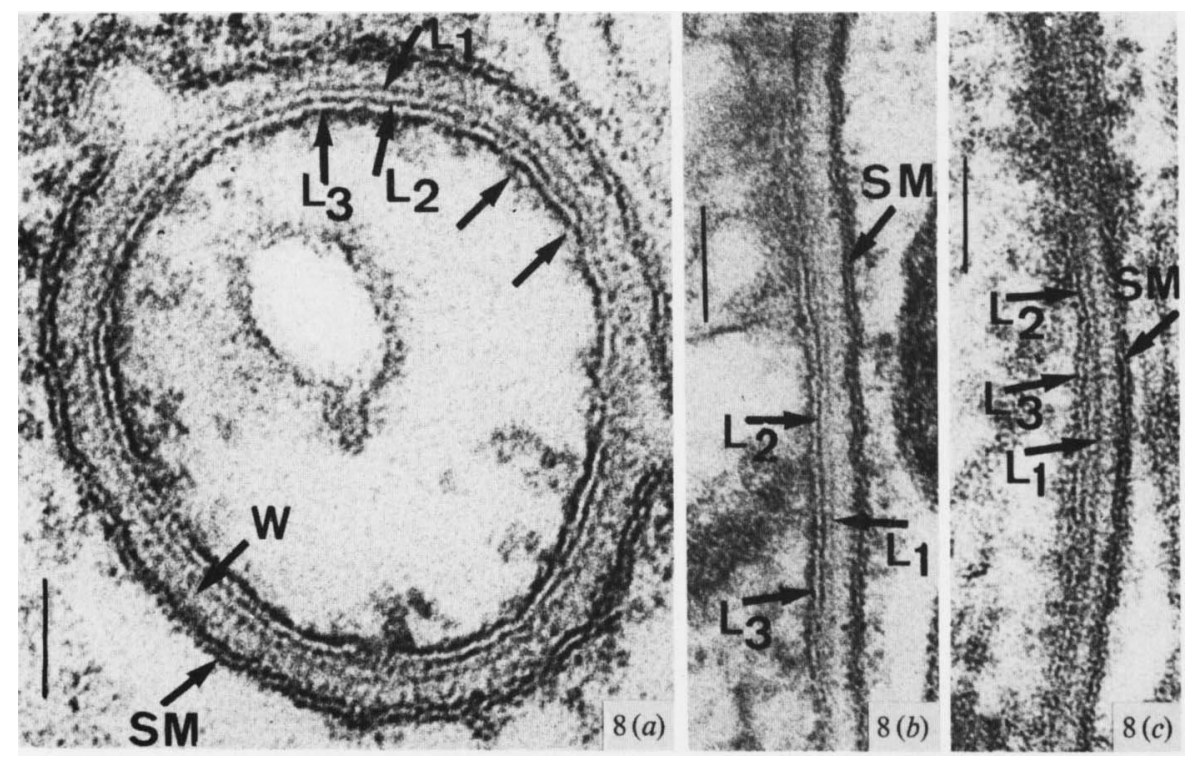

Fig. 8. Whipple bacilli free in the lamina propria and with signs of partial lysis. Fixation as in Fig. 1. The envelope layers are more clearly resolved than in intact bacilli. SM, surface membrane; $\mathbf{W}$, cell wall with the inner dense layer (L1); L2 and L3, the two electron-dense layers of the cytoplasmic membrane. Notice that in several places (e.g. in the zone between the unlabelled arrows in $a$ ) L2 and L3 follow a common trajectory that is not parallel to that of L1. Sections stained with uranyl acetate/lead. Bars, $100 \mathrm{~nm}$
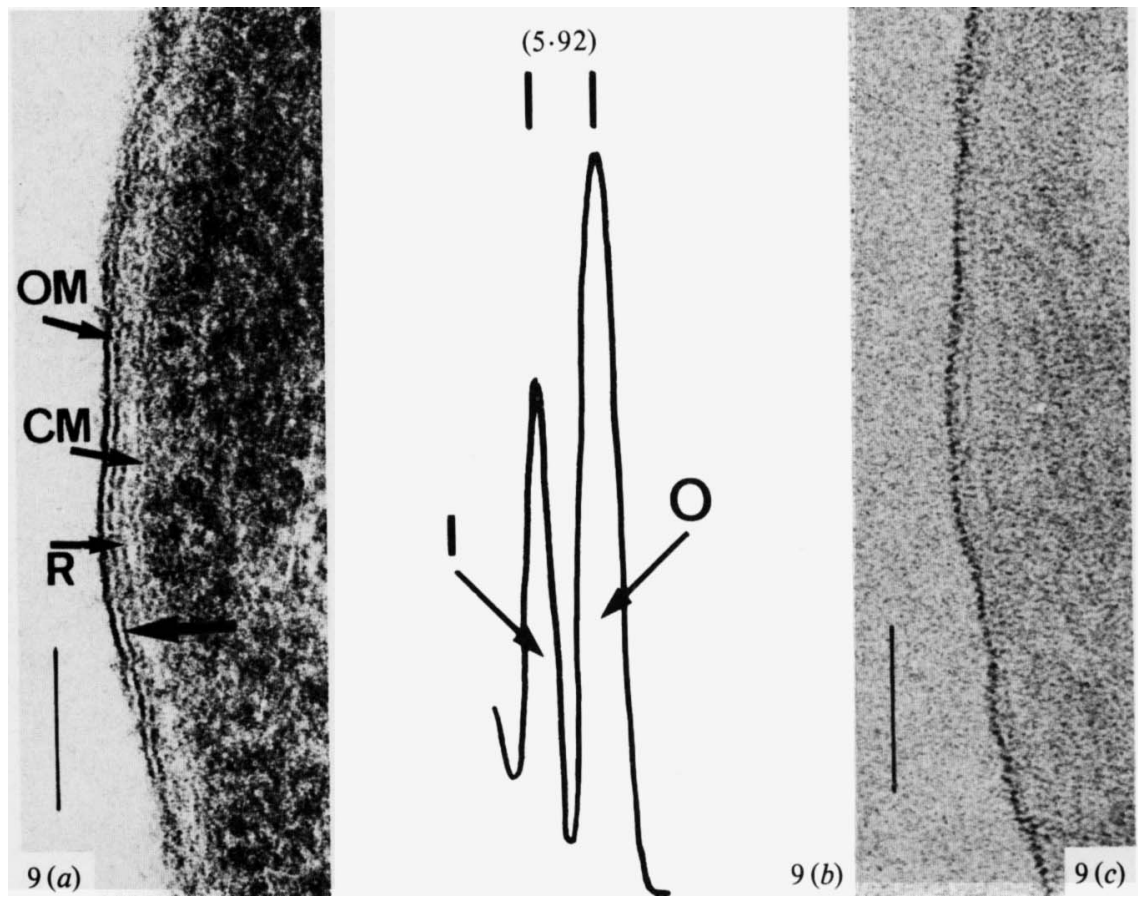

Fig. 9. Envelopes of $P$. fluorescens. (a) Sample fixed with glutaraldehyde $+\mathrm{Ca}^{2+} / \mathrm{OsO}_{4}+\mathrm{Ca}^{2+} / \mathrm{uranyl}$ acetate $(\operatorname{method} b)$. Section stained with uranyl acetate/lead. Notice the asymmetric profile of the outer membrane (OM), which has an outer layer thicker and more electron-dense than the inner layer. $R$, rigid layer (peptidoglycan); $\mathrm{CM}$, cytoplasmic membrane. (b) Microdensitometric tracing of the outer membrane in $(a)$. I, inner layer; $\mathrm{O}$, outer layer; peak-to-peak distance $(\mathrm{nm})$ in parentheses. $(c)$ Thiéry staining of the sample in $(a)$. Bars, $200 \mathrm{~nm}$. 
Influence of fixation conditions. In samples prepared with fixatives that did not include divalent cations $\left(\mathrm{Ca}^{2+}\right.$ and $\left.\mathrm{UO}_{2}^{2+}\right)$ the overall preservation of the Whipple bacillus was poor and many of the features described above were not visible. With fixation procedure $(a)$, a method that is widely used for the fixation of biopsy samples, DNA fibrils appeared aggregated and ribosomes were not visible, and the aforementioned layers of the envelope were not demonstrated (Fig. 7).

Ultrastructure of lysing extracellular Whipple bacillus. Among the bacilli found free in the lamina propria a few exhibited ultrastructural signs of lysis with clearing of the intracellular compartment. The micromorphology of lysing bacilli was useful for the interpretation of the envelope structure (Fig. 8). In the lysing cells, it was evident that L2 and L3 were the two electron-dense layers of the bacillus cytoplasmic membrane, an aspect that was frequently not clear in intact bacilli. An observation that supported this interpretation was that layers L2 and L3 always followed the same trajectory, a trajectory that sometimes was not accompanied by L1; this is seen most clearly in Figs $8(a)$ and $8(c)$.

Comparison between the geometry of the surface membrane of the Whipple bacillus and the outer membrane of Gram-negative bacteria. Fig. $9(a)$ shows the asymmetric ultrastructural profile of $P$. fluorescens outer membrane in a sample fixed by procedure $(b)$ and section-stained with uranyl acetate/lead. The corresponding microdensitometric tracing (Fig. $9 b$ ) clearly showed that the outer layer of that membrane was thicker and more electron-dense than the inner layer; the mean peak-to-peak distance was $5.92 \mathrm{~nm}$. Thiéry staining of the outer membrane of $P$. fluorescens revealed PAS-positive components in the outer layer (Fig. $9 c$ ). Similar results were obtained with $E$. coli (not shown). Statistical analysis (Student's $t$ test) of the values for the peakto-peak distances of the surface membrane of the Whipple bacillus and the outer membrane of $P$. fluorescens and $E$. coli showed that the outer membrane of the Gram-negative bacteria was significantly thicker than the surface of the Whipple bacillus $(P<0 \cdot 01)$.

Ultrastructural and cytochemical characterization of the host macrophage plasma membrane. Densitometry of the macrophage plasma membrane profile showed that it was symmetric and that the peak-to-peak distance was $4.8 \mathrm{~nm}$; statistical analysis (Student's $t$ test) of the values obtained from several measurements showed that this was not significantly different from the thickness of the Whipple bacillus surface membrane $(P>0.05)$. Moreover, no Thiéry-positive components could be detected in the macrophage plasma membrane.

Ultrastructure of the Whipple bacillus inside jejunal macrophages. Bacteria with ultrastructural signs of lysis were abundant inside phagocytic vacuoles of jejunal macrophages. This bacteriolytic process occurred in untreated patients, where a small proportion of the numerous bacilli present free in the lamina propria seemed to be susceptible to phagocytosis by macrophages. The degenerating bacteria exhibited micromorphological features that we interpreted as steps of a degradative process that eventually led to the loss of bacillary forms and to the formation of the PAS-positive inclusions typical of the disease. The following steps were characterized. (i) Disorganization of the surface membrane and of the thick wall layer outside L1, and modification of the intracellular compartment that exhibits blocks of granular material and no ribosomes (Figs 10,11 $a$ and $11 b$ ); DNA fibrils may still be present but they are digested early in the process. (ii) The intracellular material is lost (Figs 10,11b and $11 c$ ); at this stage the bacterial ghosts are reduced to the three inner layers of the envelope (L1, L2, L3) (Figs 10, $11 b$ and $11 \mathrm{c}$ ). (iii) The cytoplasmic membrane (layers L2 and L3) is disorganized and solubilized, leaving $\mathrm{Ll}$ as the final remnant of the bacilli; in Thiéry-stained sections these remnants appear as layers of PAS-positive material (Fig. 12). (iv) These Thiéry-positive structures collapse and become compressed against each other (Fig. 13), later forming compact inclusions of Thiérypositive lamellae (Fig. 14) that correspond to the PAS-positive inclusions seen in histological preparations. 


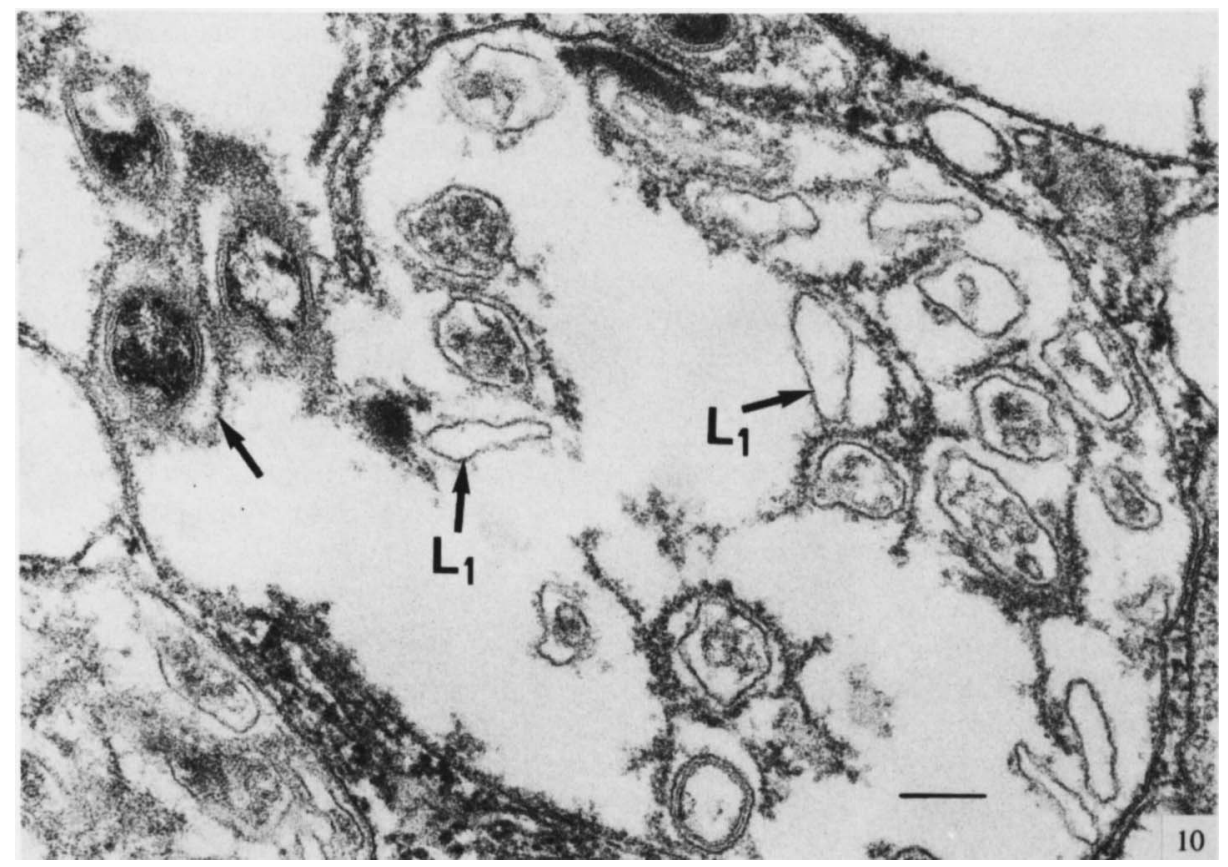

Fig. 10. A phagocytic vacuole of a jejunal macrophage with several Whipple bacilli in different stages of degeneration. In the upper left corner of the picture are three bacilli in an early stage of lysis showing disorganization of the wall material outside $\mathrm{Ll}$ (unlabelled arrow) and of the cytoplasm; the inner, electron-dense layer of the cell wall (L1) and the two electron-dense layers of the cytoplasmic membrane (L2 and L3) are still present. In some of the other degenerating bacilli the cell remnants are reduced to L1. Fixation as in Fig. 2 (method $c$ ). Section stained with uranyl acetate/lead. Bar, $200 \mathrm{~nm}$.
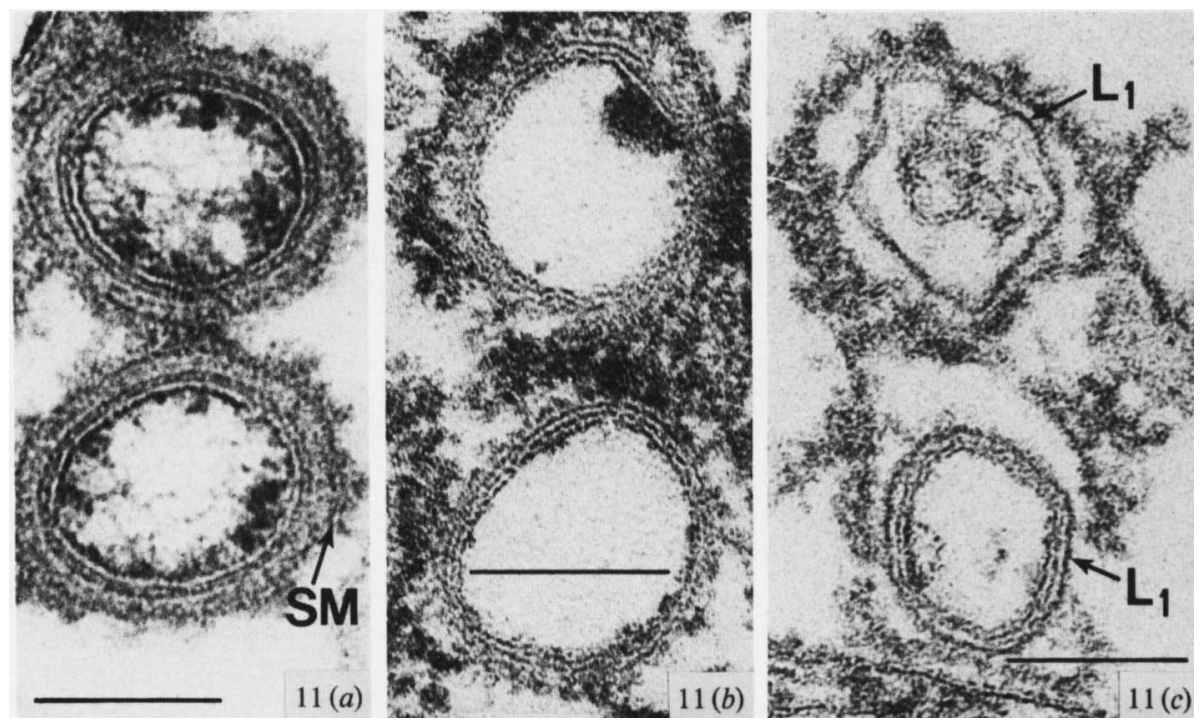

Fig. 11. Several steps of the degenerative process of Whipple bacillus inside phagocytic vacuoles of jejunal macrophages. SM, disorganized surface membrane. In most bacilli the cytoplasmic membrane and the inner layer of the wall $(\mathrm{Ll})$ are still present, but in the bacillus at the top of $(c)$ only $\mathrm{Ll}$ remains. Fixation and staining as in Fig. 10. Bars, $200 \mathrm{~nm}$. 


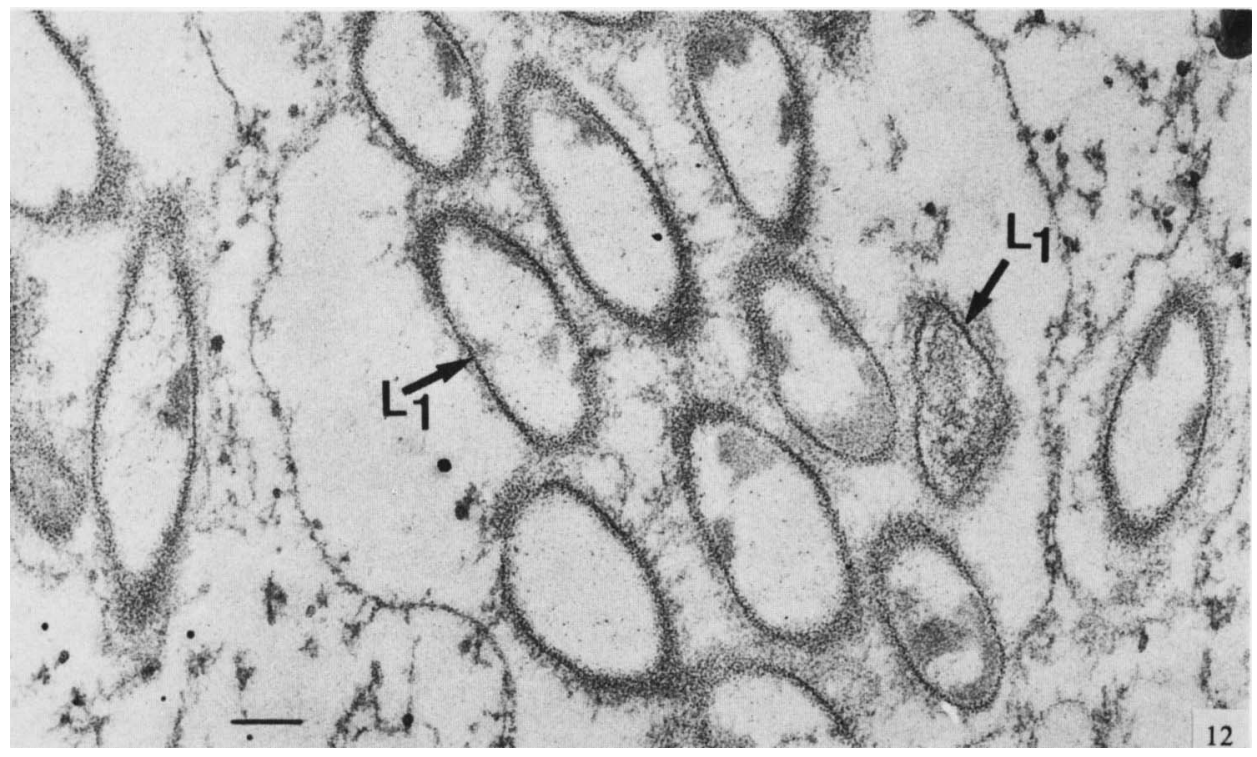

Fig. 12. Thiéry staining of degenerating Whipple bacilli in a phagocytoc vacuole of a jejunal macrophage. Notice that only the inner layer of the wall (Ll) is left and that it stains PAS-positive. Bar, $200 \mathrm{~nm}$.

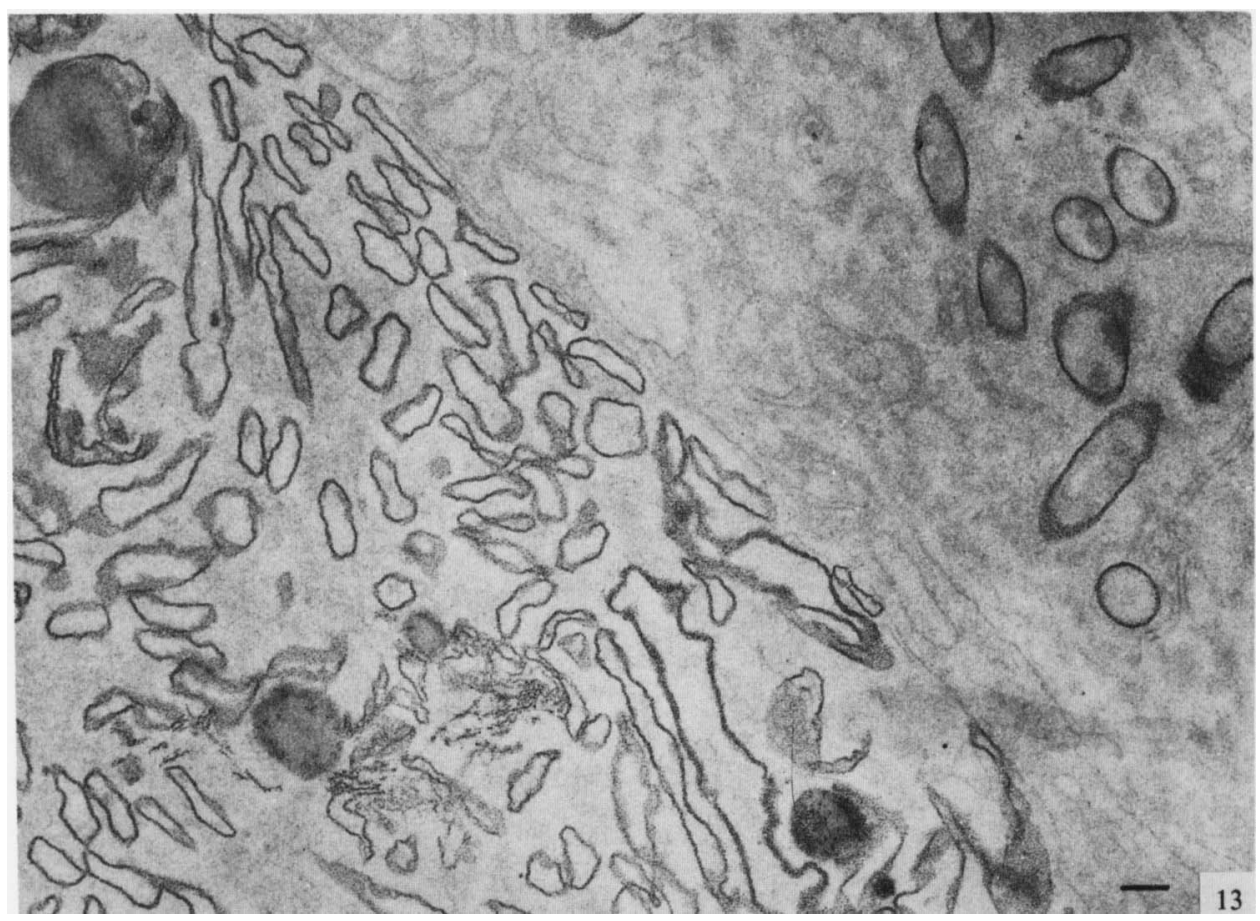

Fig. 13. Thiéry staining of a jejunal macrophage with several bacillary remnants that stain PASpositive; on the right of the picture some normal-looking bacilli are present, probably outside the macrophage. The group of deformed, Thiéry-positive lamellae are remnants of $\mathrm{Ll}$ and represent an early stage in the formation of the PAS-positive intramacrophagic inclusions. Fixation as in Fig. 10. Bar, $200 \mathrm{~nm}$. 


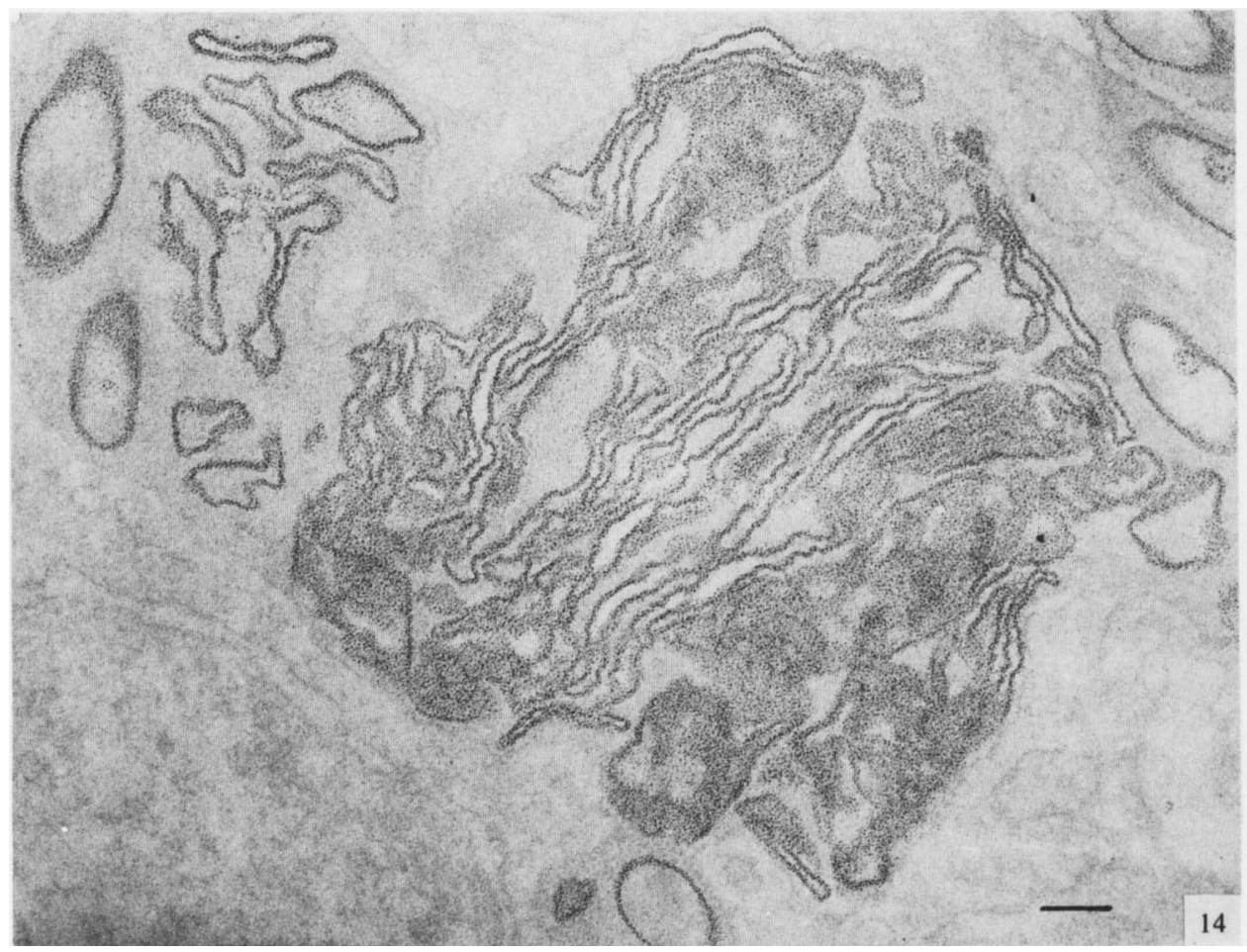

Fig. 14. As in Fig. 13, showing a more advanced stage in the formation of the PAS-positive inclusions. Notice the presence of lamellae of Thiéry positive material, some of them cut transversely, others tangentially. Fixation as in Fig. 10. Bar, $200 \mathrm{~nm}$.

\section{DISCUSSION}

Our results, obtained with fixation methods previously found to be appropriate for the preparation of bacterial cells for electron microscopy, and not used in earlier studies on this subject, allowed a better characterization of the peculiar ultrastructure of the Whipple bacillus in regard to the organization of the envelopes. These results clearly confirm our previous contention that fixation procedures that preserve eukaryotic cells well can be unsuitable for prokaryotes (Silva, 1975, 1984; Silva \& Macedo, 1983c).

Since the Whipple bacillus cannot be grown in bacteriological media, no direct analytical data are available on the chemistry of the envelope structures of the bacilli. Consequently, the aspects described in Results are interpreted in the light of the ultrastructural data and the application of cytochemical methods. Our interpretation of the organization of the envelopes of the Whipple bacillus is the following. Layers L2 and L3 represent the two electron-dense layers of the cytoplasmic membrane. This conclusion is based on the observation that whenever these two layers are clearly visible they follow the same trajectory, which sometimes is not parallel to that of L1. Due to the frequently unclear image of L3 in intact bacilli, in some pictures the cytoplasmic membrane could be erroneously interpreted as $\mathrm{Ll}+\mathrm{L} 2$, as has previously been done (Dobbins \& Kawanishi, 1981). The mean value found for the peak-to-peak distance of the cytoplasmic membrane of the Whipple bacillus $(6.08 \mathrm{~nm})$ is similar to that of other Grampositive bacteria (Silva \& Macedo, 1983a). The cell wall is the structure between L2 and the surface membrane, and $\mathrm{L} 1$ represents an inner, polysaccharide-containing layer of the wall. The presence of this layer in the wall of the Whipple bacillus has not been recognized in previous studies (Chears \& Asworth, 1961; Dobbins \& Kawanishi, 1981; Trier et al., 1965; Watson \& Haubrich, 1969). The conclusions regarding the organization of the Whipple bacillus cell wall are based on the results of the phosphotungstic acid stain and of the Thiery procedure. Phosphotungstic acid at low pH contrasts bacterial peptidoglycan (Rosseau \& Hermier, 1975; 
Silva, 1984), which is Thiéry-negative (Rosseau \& Hermier, 1975). The inner, Thiéry-positive layer of the cell wall (L1) contains polysaccharides, possibly teichoic acids, which are present in the walls of Gram-positive bacteria (Ghuysen, 1977) and are Thiéry-positive (Rosseau \& Hermier, 1975). The average thickness we found for the Whipple bacillus cell wall $(20 \mathrm{~nm})$ is in agreement with the thickness reported for the wall of most Gram-positive bacteria (Glauert \& Thornley, 1969) and is significantly higher than the reported thickness of the peptidoglycan (Rlayer) of the wall of most Gram-negative bacteria (Glauert \& Thornley, 1969; Silva \& Sousa, 1973).

So far, therefore, the Whipple bacillus envelope has the characteristics typical of Grampositive bacteria (Ghuysen, 1977; Glauert \& Thornley, 1969), but the presence of the surface membrane complicates the picture. Due to the presence of this membrane, which superficially resembles the outer membrane of Gram-negative bacteria, the Whipple bacillus has been considered as having a Gram-negative-like outer membrane (Dobbins \& Kawanishi, 1981). Our present results lead to a different conclusion. The outer membrane of Gram-negative bacteria like Escherichia and Pseudomonas contains in its outer layer a lipopolysaccharide that confers on the membrane an asymmetric geometry in lead-stained sections (Silva \& Sousa, 1973; Silva, 1984) and positive Thiéry and phosphotungstic acid stainings of its surface (Petitprez \& Derieux, 1970; Thiéry, 1967; Silva, 1984). In the case of the Whipple bacillus the surface membrane is symmetric and does not stain with the Thiéry and phosphotungstic acid techniques, indicating the absence of lipopolysaccharide. Moreover, the thickness of this membrane is significantly lower than that of the outer membrane of $P$. fluorescens and E. coli. That is, the Whipple bacillus has a cell wall structure that is in accordance with its Grampositive staining, the wall being surrounded by an additional, peculiar membrane that is different from the outer membrane of Gram-negative bacteria. It is difficult, at present, to understand the origin and functions of such a membrane. It could be of bacterial origin, as is known to occur with other Gram-positive bacteria, like Micrococcus radiodurans (Glauert \& Thornley, 1969) and M. radiophilus and M. radioproteolyticus (Sleytr et al., 1976). Interestingly, the surface membrane of the two last bacteria is Thiéry-negative (M. T. Silva, unpublished). Another alternative is that the surface membrane of the Whipple bacillus is of host origin. The fact that both the surface membrane of the Whipple bacillus and the macrophage plasma membrane are symmetric, are $4.8 \mathrm{~nm}$ thick and are Thiéry-negative, would support this hypothesis, but more information is necessary to clarify this point. Surface membranes of bacteria usually contain in their outer layer the so-called surface amphiphiles (Wicken \& Knox, 1980 ) that play an important role in pathogenicity (Wicken \& Knox, 1980). Such amphiphiles are stained by phosphotungstic acid at low $\mathrm{pH}$ and some of them are also Thiéry-positive (Petitprez \& Derieux, 1970; Thiéry, 1967; Silva, 1984). The absence of such amphiphiles in the surface of the Whipple bacillus is interesting and may be related to the peculiar infectious and immunological characteristics of Whipple's disease (Dobbins, 1981; Keren, 1981; Miksche et al., 1974).

One very characteristic feature of the histology of Whipple's disease is the presence inside macrophages of PAS-positive inclusions (Maizel et al., 1970) that have been assumed to be of bacterial origin (Chears \& Asworth, 1961; Bhagavan et al., 1981). Our present results demonstrate such an origin and further show that the inclusions are accumulations of a particular, polysaccharide-containing layer of the Whipple bacillus envelope (L1).

Our results show that two types of lytic process can affect the bacilli in untreated patients. (i) The lysis of bacilli while free in the intercellular spaces of the jejunal lamina propria seems to result from autolytic activity, since such bacilli are not inside phagolysosomes; during the initial lytic process, the intracellular compartment appears clarified while the surface membrane of the bacilli remains ultrastructurally unaffected. (ii) The degradative process that occurs inside the macrophage phagocytic vacuoles is probably the result of the hydrolytic action of the macrophage on the phagocytosed bacilli; it is characterized by an early disorganization of the bacillus surface membrane. It seems that the occurrence of these two types of lytic degradation of bacilli in untreated patients was insufficient to prevent the progress of the disease, which was controlled only after antibacterial therapy. 
We found almost no normal-looking Whipple bacilli inside jejunal macrophages. The vast majority of normal bacilli, including some undergoing division, were present free in the lamina propria. The bacilli that were phagocytosed by macrophages were being degraded. Thus, the Whipple bacillus appears to grow extracellularly; phagocytosis by macrophages is followed by the death and partial degradation of the bacteria. This picture differs from that observed in infections by intracellular parasitic bacteria like, for example, mycobacteria. The extracellular growth of the Whipple bacillus and its subsequent degradation by macrophages are not like the reports for jejunal infection with Mycobacterium avium-intracellulare in patients with acquired immunodeficiency syndrome (AIDS) (Fainstein et al., 1982; Gillin et al., 1983; Strom \& Grunninger, 1983) or for lepromatous leprosy, where bacillary growth occurs inside macrophages. In Whipple's disease the rate of phagocytosis appears to be insufficient to cope with bacillary growth, so that the number of bacteria increases in untreated patients; the bacilli ingested by macrophages are unable to grow and are degraded.

We are grateful to Dr F. Taverela Veloso (School of Medicine, University of Porto), to Drs I. Cruz and A. Freitas (District Hospital of Setubal) and to Drs M. Beatriz Beija and I. Soares (District Hospital of Cascais) for the jejunal biopsies, to Miss M. Irene Barros for excellent technical assistance and to Mrs M. Andrea Costa for help in the photographic work.

The present work was supported in part by INIC (Lisboa) (grant PB/1), by JNICT (Lisboa) (grant 435.82.110) and by Fundação Calouste Gulbenkian (grant to P.M.M.). The Elmiskop 102 used in this work was a gift from Stiftung Volkswagenwerke (Hannover).

\section{REFERENCES}

Bhagavan, B. S., Hofkin, G. A. \& Cochran, B. A. (1981). Whipple's disease: morphologic and immunofluorescence characterization of bacterial antigens. Human Pathology 12, 930-936.

Chears, W. C. \& Asworth, C. T. (1961). Electron microscopic study of the intestinal mucosa in Whipple's disease. Gastroenterology 41, 129-137.

DobBINS, W. O., III (1981). Is there an immune deficit in Whipple's disease? Digestive Disease Science 26, $247-252$.

Dobbins, W. O., III \& KaWANISHI, H. (1981). Bacillary characteristics in Whipple's disease: an electron microscopy study. Gastroenterology 80, 1468-1475.

Dobbins, W. O., III \& Ruffin, J. M. (1967). A light and electron microscope study of bacterial invasion in Whipple's disease. American Journal of Pathology 51, 225-242.

Fainstein, V., Boliram, R., Mavligit, G., Rios, A. \& LUNA, M. (1982). Disseminated infection due to Mycobacterium avium-intracellulare in a homosexual man with Kaposi's sarcoma. Journal of Infectious Diseases 145, 586.

GHUYSEN, J. M. (1977). Biosynthesis and assembly of bacterial cell walls. In The Synthesis, Assembly and Turnover of Cell Surface Components, pp. 463-595. Edited by G. Poste \& G. Nicolson. Amsterdam \& New York: North-Holland Publishing Co.

Gillin, J. S., Urmacher, C., West, R. \& Shuke, M. (1983). Disseminated Mycobacterium avium-intracellulare infection in acquired immunodeficiency syndrome mimicking Whipple's disease. Gastroenterology 85, 1187-1191.

Glauert, A. M. \& Thornley, M. J. (1969). The topography of the bacterial cell wall. Annual Review of Microbiology 23, 159-198.

Hayat, M. A. (1970). Principles and Techniques of Electron Microscopy, vol. I. New York: Van Nostrand Rheinhold Co.
KEREN, D. F. (1981). Whipple's disease: a review emphasizing immunology and microbiology. $C R C$ Critical Reviews in Clinical and Laboratory Science 14, 75-108.

Keren, D. F., Weisburger, W. R., Yardley, J. H., Salyer, W. R., Arthur, R. R. \& Charade, P. (1976). Whipple's disease: demonstration by immunofluorescence of similar bacterial antigens in macrophages from three cases. Johns Hopkins Medical Journal 139, 51-59.

LUFT, J. H. (1961). Improvements in epoxy resin embedding methods. Journal of Biophysical and Biochemical Cytology 9, 409-414.

Macedo, P. M. \& Silva, M. T. (1983). Morphogenesis of the PAS-positive inclusions of macrophages in Whipple's disease. XVIII Reunião Anual, Sociedade Portuguesa Microscopia Electrónica, abstract 70.

Maizel, H., Ruffin, J. M. \& Dobbins, W. O., III (1970). Whipple's disease: a review of 19 patients from one hospital and a review of the literature since 1950. Medicine 49, 175-205.

Miksche, L. W., Blumke, S., Fritsche, D., KucheMANN, K., Schuler, H. W. \& Grozinger, K. H. (1974). Whipple's disease: ethiopathogenesis, treatment, diagnosis and clinical course. Case report and review of the world literature. Acta hepato-gastroenterologica 21, 307.

Palade, G. E. (1952). A study of fixation for electron microscopy. Journal of Experimental Medicine 95, 285-298.

Petitprez, A. \& Derieux, J. C. (1970). Mise en évidence des polysaccharides sur quelques types de bactéries. Journal de microscopie 9, 263-272.

Rambourg, A. (1971). Morphological and histochemical aspects of glycoproteins of the surface of animal cells. International Review of Cytology 31, 57-114.

Rosseau, M. \& Hermier, J. (1975). Localization en microscopie électronique des polysaccharides de la 
paroi chez les bactéries en sporulation. Journal de microscopie 23, 237-248.

ROTH, R. I., OWEN, R. L. \& KeREN, D. F. (1983). Letter to New England Journal of Medicine 309, 1324.

Ryter, A. \& Kellenberger, E. (1958). Étude au microscope électronique de plasmas contenant de l'acide désoxyribonucléique. I. Les nucléoides des bactéries en croissance active. Zeitschrift für Naturforschung 13b, 597-605.

SiLva, M. T. (1971). Changes induced in the ultrastructure of the cytoplasmic and intracytoplasmic membranes of several Gram-positive bacteria by variations in $\mathrm{OsO}_{4}$ fixation. Journal of Microscopy 93, 227-232.

Silva, M. T. (1975). Ultrastructure of the membranes of Gram-positive bacteria as influenced by fixatives and membrane-damaging treatments. In Biomembranes-Lipids, Proteins and Receptors, pp. 255-289. Edited by R. M. Burton \& L. Packer. Webster Groves, Mo., USA: BI-Science Publication Division.

Silva, M. T. (1984). The use of transmission electron microscopy of ultrathin sections for the characterization of the ultrastructure of normal and damaged bacterial membranes. In Biomembranes: Dynamics and Biology, pp. 1-36. Edited by F. C. Guerra \& R. M. Burton. New York: Plenum Press.

Silva, M. T. \& MACEDO, P. M. (1982). Ultrastructure of Mycobacterium leprae and other acid-fast bacteria as influenced by fixation conditions. Annales de microbiologie 133B, 59-73.

SIlva, M. T. \& MACEDO, P. M. (1983a). A comparative ultrastructural study of the membranes of Mycobacterium leprae and of cultivable mycobacteria. Biology of the Cell 47, 383-386.

Silva, M. T. \& MaCEDO, P. M. (1983b). Electron microscopic study of Mycobacterium leprae membrane. International Journal of Leprosy 51, 219224.

Silva, M. T. \& Macedo, P. M. (1983c). The interpretation of the ultrastructure of $M_{y}$ cobacterium cells in transmission electron microscopy of ultrathin sections. International Journal of Leprosy 51, 225234.

Silva, M. T. \& MACEDO, P. M. (1983d). Ultrastructural and cytochemical study of Whipple bacillus. XVIII Reunião Anual, Sociedade Portuguesa Microscopia Electrónica, abstract 69.

Silva, M. T. \& SouSA, J. C. F. (1973). Ultrastructure of the cell wall and cytoplasmic membrane of Gramnegative bacteria with different fixation techniques. Journal of Bacteriology 113, 953-962.

Silva, M. T., Macedo, P. M., Salema, R. \& Santos, I. (1982). Improvement in the Thiéry reaction by the use of silver vitelinate. XVII Reunião Anual, Sociedade Portuguesa Microscopia Electrónica, abstract 30.

Sleytr, V. O., Silva, M. T., Kocur, M. \& Lewis, N. F. (1976). The fine structure of Micrococcus radiophilus and $M$. radioproteolyticus. Archiv fur Mikrobiologie 107, 313-320.

Strom, R. L. \& Grunninger, R. P. (1983). Letter to New England Journal of Medicine 309, 1323-1324.

THIÉRY, J.P. (1967). Mise en évidence des polysaccharides sur coupes fines en microscopie électronique. Journal de microscopie 6, 987-1019.

ThiÉRY, J. P. \& RambourG, A. (1974). Citochimie des polysaccharides. Journal de microscopie 21, 225-232.

Trier, J. S., Phelps, P. C., Eidelman, S. \& Rubin, C. E. (1965). Whipple's disease: light and electron microscope correlation of jejunal mucosa histology with antibiotic treatment and clinical status. Gastroenterology 48, 684-707.

Venable, J. H. \& Coggeshall, R. (1965). A simplified lead citrate stain for use in electron microscopy. Journal of Cell Biology 25, 407-408.

WATSON, J. H. L. \& HAUBRICH, S. (1969). Bacilli bodies in the lumen and epithelium of the jejunum in Whipple's disease. Laboratory Investigation 21, 347357.

WICKEN, A. J. \& KNox, K. W. (1980). Bacterial cell surface amphiphiles. Biochimica et biophysica acta 604, 1-26. 